\title{
Article \\ Changes in Hippocampus and Amygdala Volume with Hypoxic Stress Related to Cardiorespiratory Fitness under a High-Altitude Environment
}

\author{
Zhi-Xin Wang ${ }^{1}{ }^{(\mathbb{D}}$, Rui Su ${ }^{1} \mathbb{D}$, Hao Li $^{1}$, Peng Dang ${ }^{1}$, Tong-Ao Zeng ${ }^{1}$, Dong-Mei Chen ${ }^{1}$, Jian-Guo Wu ${ }^{2}$, \\ De-Long Zhang ${ }^{1,3, *}$ and Hai-Lin Ma ${ }^{1, *}$
}

Citation: Wang, Z.-X.; Su, R.; Li, H.; Dang, P.; Zeng, T.-A.; Chen, D.-M.; Wu, J.-G.; Zhang, D.-L.; Ma, H.-L. Changes in Hippocampus and Amygdala Volume with Hypoxic Stress Related to Cardiorespiratory Fitness under a High-Altitude Environment. Brain Sci. 2022, 12, 359. https://doi.org/10.3390/ brainsci12030359

Academic Editor: Filipe Manuel Clemente

Received: 11 February 2022 Accepted: 26 February 2022 Published: 8 March 2022

Publisher's Note: MDPI stays neutral with regard to jurisdictional claims in published maps and institutional affiliations.

Copyright: (C) 2022 by the authors. Licensee MDPI, Basel, Switzerland. This article is an open access article distributed under the terms and conditions of the Creative Commons Attribution (CC BY) license (https:// creativecommons.org/licenses/by/ $4.0 /)$.
1 Plateau Brain Science Research Center, Tibet University/South China Normal University, Lhasa 850012, China; wangzhixin666@outlook.com (Z.-X.W.); srsisu2011@163.com (R.S.); futanghu888@126.com (H.L.); 18932689504@163.com (P.D.); tsangtongao@gmail.com (T.-A.Z.); chendongmei0228@163.com (D.-M.C.)

2 Management Department, Tibet Police College, Lhasa 850012, China; wjg198228@163.com

3 Key Laboratory of Brain, Cognition and Education Sciences, Center for Studies of Psychological Application, Guangdong Key Laboratory of Mental Health and Cognitive Science, Ministry of Education, School of Psychology, South China Normal University, Guangzhou 510631, China

* Correspondence: delong.zhang@m.scnu.edu.cn (D.-L.Z.); David_ma79@163.com (H.-L.M.)

\begin{abstract}
The morphology of the hippocampus and amygdala can be significantly affected by a longterm hypoxia-induced inflammatory response. Cardiorespiratory fitness (CRF) has a significant effect on the neuroplasticity of the hippocampus and amygdala by countering inflammation. However, the role of CRF is still largely unclear at high altitudes. Here, we investigated brain limbic volumes in participants who had experienced long-term hypoxia exposure in Tibet (3680 m), utilizing highresolution structural images to allow the segmentation of the hippocampus and amygdala into their constituent substructures. We recruited a total of 48 participants (48 males; aged $=20.92 \pm 1.03$ years) to undergo a structural 3T MRI, and the levels of maximal oxygen uptake $\left(\mathrm{VO}_{2 \mathrm{max}}\right)$ were measured using a cardiorespiratory function test. Inflammatory biomarkers were also collected. The participants were divided into two groups according to the levels of median $\mathrm{VO}_{2 \mathrm{max}}$, and the analysis showed that the morphological indexes of subfields of the hippocampus and amygdala of the lower CRF group were decreased when compared with the higher CRF group. Furthermore, the multiple linear regression analysis showed that there was a higher association with inflammatory factors in the lower CRF group than that in the higher CRF group. This study suggested a significant association of CRF with hippocampus and amygdala volume, which may be related to hypoxic stress in high-altitude environments. A better CRF reduced physiological stress and a decrease in the inflammatory response was observed, which may be related to the increased oxygen transport capacity of the body.
\end{abstract}

Keywords: high altitude; cardiorespiratory fitness; stress; amygdala; hippocampus

\section{Introduction}

Under a high-altitude environment, the decrease in atmospheric pressure and the consequent drop in the partial pressure of oxygen $\left(\mathrm{PO}_{2}\right)$ can result in hypobaric hypoxia. The human brain is the most oxygen-consuming organ, and is very susceptible to hypoxic stress [1]. Hypoxic stress has serious effects on brain structures, such as the hippocampus and amygdala [2-4]. Behavior and brain structure changes arising from hypoxia can be observed in a real high-altitude environment, and examined in simulated hypoxia situations. The hypoxia impact on the brain exhibits a significant altitude-dependent effect $[5,6]$.

Activation of the hypothalamic-pituitary-adrenal axis (HPA) is a hallmark of the stress response [7]. At the level of the organism, a hypoxic challenge is perceived as a non-specific stress, and hypoxia could upregulate the setpoint of the HPA axis and augment adrenal steroidogenic production, resulting in neuroinflammation and neuronal cell death [8]. Highaltitude hypoxia stress affects a wide range of brain areas [4,9]. Major brain regions with 
structural and functional abnormalities are particularly vulnerable to hypoxic stress, including the amygdala and hippocampus [8]. Changes in the amygdala and hippocampus under high-altitude hypoxia stress may be due to the influence of inflammation $[10,11]$. The inflammatory response to hypoxia leads to the death of hippocampal neurons [12,13]. Similar studies have found that after hypoxia stress, the inflammatory response of the hippocampus and amygdala increase, leading to the death of neurons [14,15]. Studies of hypoxia stress in the brain caused by human disease have also found that inflammation can trigger neuron damage in the hippocampus and amygdala [14]. The number of corticotropin-releasing factor- (CRF-) and neuropeptide-Y- (NPY-) positive neurons were found to be decreased in the amygdala after hypoxia-ischemia [16]. In conclusion, inflammation caused by altitude hypoxia stress seriously affects the hippocampus and amygdala.

Cardiorespiratory fitness (CRF) is an objective measure of habitual physical activity that reflects the overall capacity of the cardiorespiratory system, and has been used to assess the relationship between physical activity and health status [17]. Increasing evidence has shown that higher levels of CRF are related to better brain health [18]. Improving CRF can effectively maintain the axial homeostasis of the HPA and reduce the inflammatory response $[19,20]$. CRF reduces stress-induced inflammation and increases neuroplasticity in the hippocampus and amygdala [21]. For example, higher CRF was found to be associated with greater GM volumes in several AD-relevant brain regions, including the hippocampus and amygdala [22]. The $\mathrm{CRF}$ measured using $\mathrm{VO}_{2 \max }$ was reported to be associated with the volumetric enlargement of the hippocampal head, specifically the head region of CA1 [23]. Studies in adolescents and older adults have shown that CRF levels are associated with a greater hippocampal volume [24,25]. CRF protects neurons in the amygdala and hippocampus against Alzheimer's disease-related degeneration, probably via enhancements of brain-derived neurotrophic factor (BDNF) signaling pathways and A $\beta$ clearance [26].

Cardiorespiratory function is an effective indicator for evaluating oxygen transport capacity [27]. Cardiorespiratory function is a term that can be used interchangeably with $\mathrm{CRF}$, and indicates the $\mathrm{VO}_{2 \max }$ or ability to undertake aerobic exercises [28]. Recent studies have shown that the acclimatization and adaptive processes at high altitude in healthy individuals, with tissue hypoxia, often lead to compromised arterial oxygenation [29]. However, CRF can improve oxygen transport at high altitudes [30]. This may be associated with a lower mean RBC age, thereby improving oxygen release and increasing tissue oxygen supply [31]. At the same time, the increase in CRF improves the affinity between hemoglobin and oxygen [32]. An increase in CRF is accompanied by an increase in brain blood flow and brain metabolism [33]. In summary, CRF is an important indicator of the cardiovascular system's ability to deliver oxygen to peripheral tissues, and the tissue's ability to use that oxygen [34]. Not surprisingly, CRF is involved in adaptation to high altitudes [35].

However, it is still largely unclear whether and how the CRF regulates the impact of hypoxia on the brain under high-altitude hypoxia environments. The present study aimed to explore the relationship between the volume of the hippocampus and amygdala with CRF across participants under a high-altitude environment in Tibet $(3680 \mathrm{~m})$. The study recruited participants who had been exposed to high altitudes for more than 2 years. $\mathrm{VO}_{2 \max }$ was used to measure CRF via a specialized cardiorespiratory function test system, and participants were divided into high and the low-CRF groups based on levels of median $\mathrm{VO}_{2 \max }$. MRI data were collected to segment the hippocampus and amygdala volumes, and the relationship between the hippocampal and amygdala subregions and the $\mathrm{VO}_{2 \max }$ was evaluated. To further explore the effect of CRF on the hippocampus and amygdala, we also collected biochemical indicators related to inflammation and immunity to identify the physical essence of the linkage of the hippocampus and amygdala with CRF in these immigrant participants. 


\section{Materials and Methods}

\subsection{Participants}

This study recruited a total of 48 right-handed male participants who were born in and grew up in low altitude areas, and had migrated to high-altitude areas (Lhasa, $3680 \mathrm{~m}$ ) for more than 2 years. The participants were divided into the high-CRF group $(n=23)$ and the low-CRF group $(n=25)$ according to their median $\mathrm{VO}_{2 \max }$. In addition, the sample size was reasonable, which was measured using the $\mathrm{G}^{*}$ Power $(t=2.01$, effect size was 0.83).

All the participants had normal vision or corrected vision, and none of them had a history of mental illness or major diseases such as traumatic brain injury, hypertension, or heart disease. The two groups were matched on age (20.92 \pm 1.03 years) and years of education (14.13 \pm 0.33 years) (Table 1$)$.

Table 1. Independent sample $\mathrm{T}$ test of demographic characteristics in the low- and high-CRF groups (mean $\pm \mathrm{SD}$ ).

\begin{tabular}{|c|c|c|c|c|}
\hline & Low & High & $t$ & $p$ \\
\hline Age & $21.00 \pm 1.00$ (years) & $\begin{array}{c}20.83 \pm 1.07 \\
\text { (years) }\end{array}$ & 0.58 & 0.56 \\
\hline BMI & $20.64 \pm 3.34$ & $21.65 \pm 1.95$ & -1.26 & 0.20 \\
\hline Education & $14.08 \pm 0.28$ (years) & $\begin{array}{c}14.17 \pm 0.39 \\
\text { (years) }\end{array}$ & -0.97 & 0.34 \\
\hline Multimedia & $6.04 \pm 2.62$ (hours) & $\begin{array}{c}5.57 \pm 1.59 \\
\text { (hours) }\end{array}$ & 0.75 & 0.46 \\
\hline
\end{tabular}

This study was approved by the local ethics committee of Tibet University, and conducted in accordance with relevant guidelines and regulations. All the participants voluntarily participated in the experiment, signed the informed consent before the experiment, and received a payment after the end of the experiment.

\subsection{Experimental Design}

Forty-eight male participants who had lived in Lhasa for more than two years were randomly selected, and their $\mathrm{VO}_{2 \text { max }}$ was measured using a cardiopulmonary exercise test (CPET). Participants were divided into the low- and high-CRF groups based on their median $\mathrm{VO}_{2 \max }$. MRI data and biochemical indicators related to inflammation were collected. Then, we tested the difference between the two groups on the subfield volume and the biochemical indicators. An across-subject regressive analysis between the biochemical parameters and the regions of the hippocampal and amygdala subfields was calculated within each group (Figure 1).

\subsection{Maximum Oxygen Uptake}

CRF was assessed with CPET. Oxygen, carbon dioxide, and respiratory flow data were collected in two conditions: during rest state and during exercise state (increased load pedal powered bicycle). During the test condition, an incremental protocol with a $30 \mathrm{~W}$ per two minutes stepwise was used to test exhaustion on a cycle ergometer. The power bike load was carried out in frequency independent mode at 60 RPM, with an accuracy of $5 \mathrm{~W}$. In the preparation stage, the participants were asked to sit quietly for five minutes, and in the recovery phase, the original load was terminated and changed to $30 \mathrm{~W}$. Heart rate and oxygen uptake were measured continuously during the CPET (MetaLyzer 3B, Cortex Medical GmbH, Leipzig, Germany), and the relevant indicators were calculated according to the standard Wasserman formula [36]. The $\mathrm{VO}_{2 \mathrm{max}}\left(\mathrm{mL} \cdot \mathrm{kg} \cdot \mathrm{min}^{-1}\right)$ values were applied to completely characterize the aerobic predispositions of the participants. Prior to the measurement of each participant, the device was recalibrated [37]. Maximal efforts were assumed when the participant felt exhausted, had a heart rate greater than 180, or had a respiratory exchange rate (RER) equal to or exceeding 1.1. 


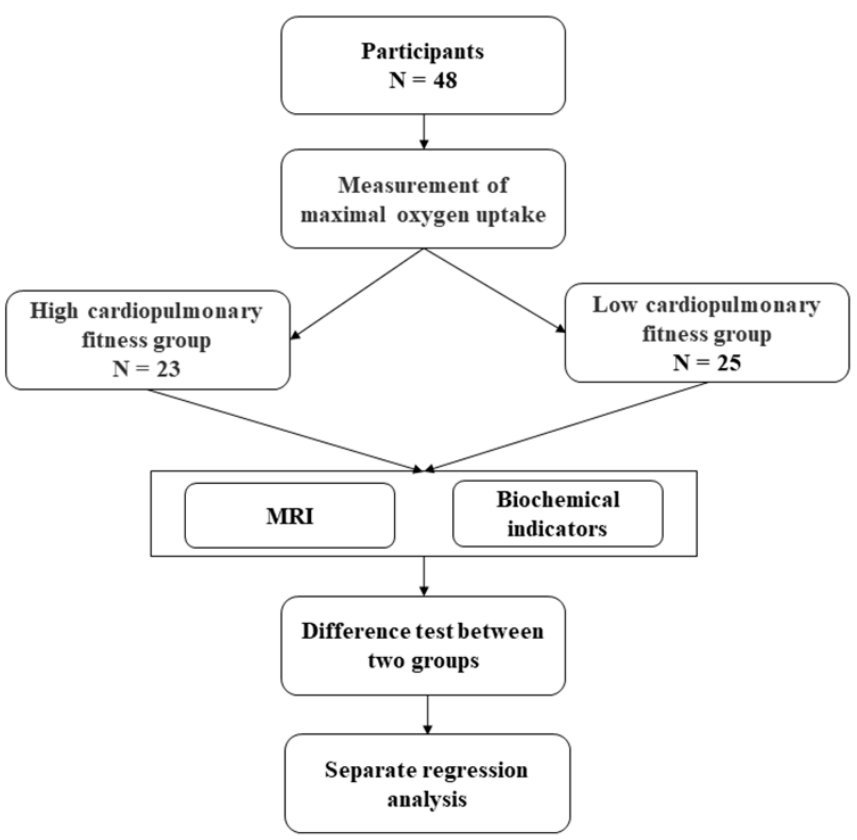

Figure 1. Study design.

\subsection{MRI Data Acquisition}

T1 weighted images were collected by a Siemens 3 Tesla Allegra MRI scanner at the Tibet Armed Police Corps Hospital using a magnetization-prepared rapid gradient-echo (MP-RAGE) sequence with the following parameters: slice thickness $=1 \mathrm{~mm}$, TR $=1900 \mathrm{~ms}$, $\mathrm{TE}=2.41 \mathrm{~ms}, \mathrm{FA}=9^{\circ}, \mathrm{FOV}=256 \mathrm{~mm}$, matrix $=256 \times 256$, slices $=192$, voxel size $=1 \mathrm{~mm}^{3}$.

T1 weighted data were processed using Freesurfer 7.1 .1 (http://surfer.nmr.mgh. harvard.edu, accessed on 25 February 2022) and MATLAB 2014 Runtime (https: / / surfer. nmr.mgh.harvard.edu/fswiki/MatlabRuntime, accessed on 25 February 2022). The standard volumetric pipeline was used to generate several files, including the Talairach transformation matrix for hippocampal and amygdaloid subfields segmentation. After the volumetric pipeline, quality control was performed to manually check the results of the brain extraction, Talairach transformation, and brain segmentation.

The automated segmentation of the hippocampal and amygdaloid subfields was driven by a probabilistic atlas and a Bayesian inference model, which maximized the probability of the segmentation [38,39]. A total of 64 structural subfields were extracted, including 20 amygdaloid subfields and 44 hippocampal subfields, as shown in Figure 2 . The subfields of the amygdala included the mean volume of the lateral nucleus, basal nucleus, accessory basal nucleus, anterior amygdaloid area, central nucleus, medial nucleus, cortical nucleus, corticoamygdaloid transition, and paralaminar nucleus, and the whole amygdala was located at the bilateral hemispheres. The total of 44 hippocampal subfields included the mean volume of the hippocampal tail, subiculum body, cornuammonis (CA) 1 body, CA1 head, subiculum head, hippocampal fissure, presubiculum head, presubiculum body, parasubiculum, molecular layer head, molecular layer body, granule cell layers of the dentate gyrus (GC-DG) head, GC-DG body, CA3 body, CA3 head, CA4 head, CA4 body, fimbria, hippocampal amygdala transition area, hippocampal body, and hippocampal head, and the whole hippocampus was located in the bilateral hemispheres. Then, the volumes of the amygdala subfields and hippocampus subfields were extracted for statistical analysis. 


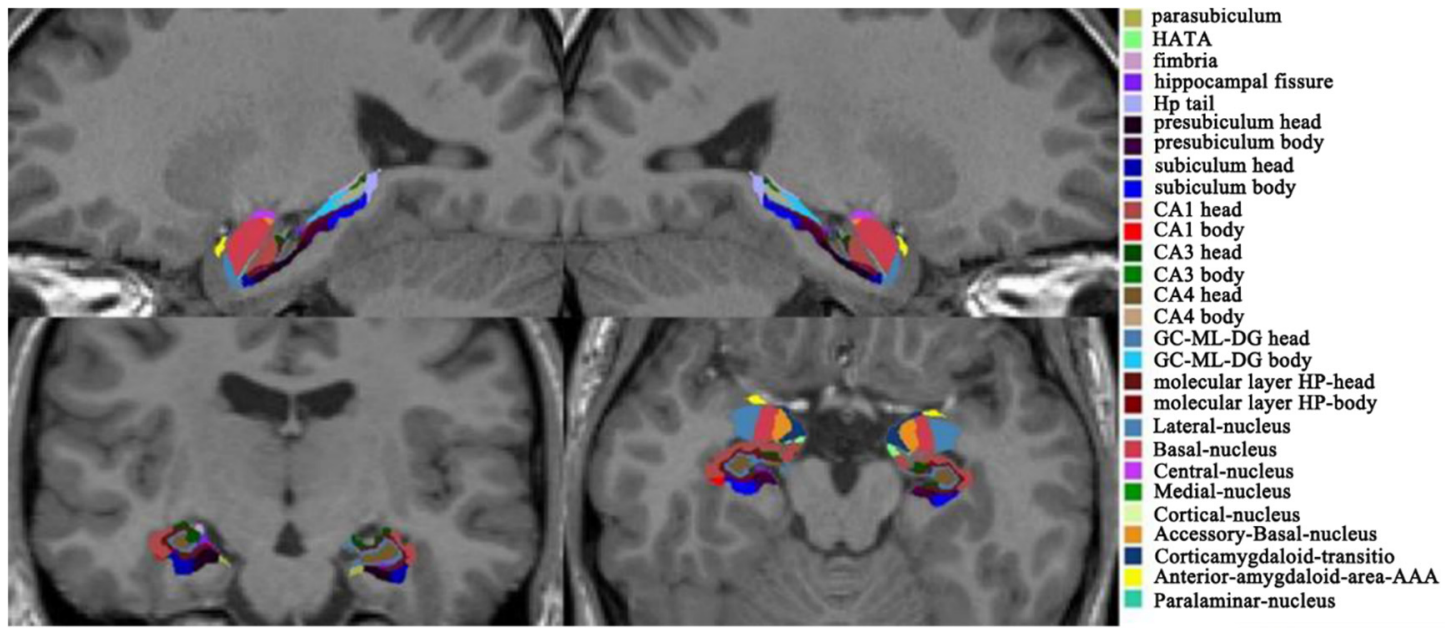

Figure 2. Subfields of the amygdala and hippocampus. CA, cornuammonis; HATA, hippocampal amygdala transition area; GC_ML_DG: granule cell layers of the dentate gyrus.

\subsection{Biochemical Indicators}

The biochemical indicators related to inflammation were collected from the participants by venous blood sampling in Fukang Hospital, affiliated with Tibet University (Lhasa, Tibet), corresponding to a previous study in our lab [40].

\subsection{Statistical Analysis}

Statistical analyses of the hippocampal subfields' volume, amygdala subfields' volume, and biochemical indicators were performed with SPSS (SPSS 20, inc./IBM, Armonk, NY, USA). We carried out the Shapiro-Wilk test first and found that the data was normally distributed $(p>0.05)$. The hippocampal subfield volume and amygdala subfield volume were tested using the analysis of covariance (ANCOVA). The ratios of the hippocampal and amygdala volume to intracranial volume were used as covariables [41]. An independent sample T test was used for the biochemical indicators, and the alpha level was set at $p<0.05$.

To test our hypothesis, the standard multiple linear regression analysis was used to analyze the relationship between the biochemical parameters and the volume of the hippocampus and amygdala subfields in each group, in which the biochemical parameters were employed as the independent factors and the volume of the target regions as the dependent factor. Notably, only the related biochemical parameters of the existing phase were input into the stepwise regression model, and the regression analyses were controlled for age and ratio of hippocampal and amygdala volume to intracranial volume by the addition of variables into the linear model as covariates [42]. Durbin-Watson tests were performed to ensure independence of errors (residuals). We checked the tolerances and correlation coefficients to make sure that there were no collinearity problems in our data set. The assumptions of linearity, error independence, homoscedasticity, outliers, and residual normality had to be satisfied before the results which could be interpreted. The multiple linear regression hypothesis was satisfied. The significance level was assumed at $p<0.05$, and $p$-values were corrected for multiple comparisons using the FDR correction [43].

\section{Results}

\subsection{Hippocampal and Amygdala Subfields}

High CRF $(2.18 \pm 0.20)$ was significantly higher than that of the low CRF $(1.62 \pm 0.15)$ $(t=-10.84, p<0.001$; Figure 3A). Analysis of covariance (ANCOVA) revealed that the left GC_ML_DG head volume $(F=4.71, p=0.035)$, the left CA4 head volume $(F=4.75, p=0.035)$, the right subiculum body volume $(F=4.34, p=0.043)$, and the right presubiculum body volume $(F=9.06, p=0.004)$ in the hippocampus of the high-CRF group were significantly larger than those of the low-CRF group. As regards the amygdala subfields, we found that 
the left corticoamygdaloid transition volumes $(F=0.465, p=0.036)$ in the high-CRF group were significantly larger than in the low-CRF group (Figure 3B).
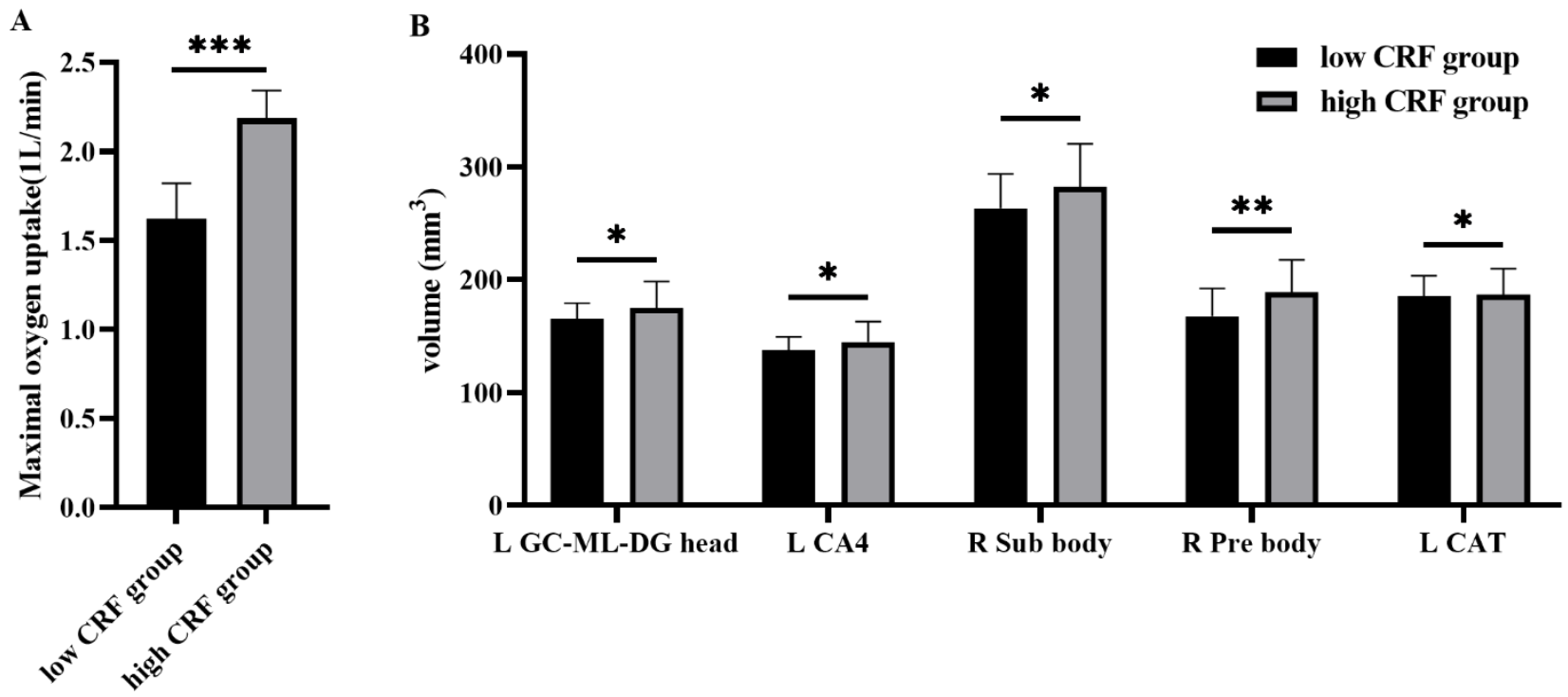

Figure 3. (A) The difference in maximal oxygen uptake between the two groups; (B) Differences between the hippocampal and amygdala subfields. L, left hemisphere; R, right hemisphere; CRF, cardiorespiratory fitness; GC-ML-DG head: granule cell layers of the dentate gyrus; CA4: cornuammonis 4; Sub body: subiculum body; Pre body: presubiculum body; CAT: corticoamygdaloid transition; ${ }^{*} p \leq 0.05 ;{ }^{* *} p \leq 0.01 ;{ }^{* * *} p \leq 0.001$.

\subsection{Biochemical Indicators}

An independent sample $\mathrm{T}$ test revealed that the direct bilirubin (DBIL), total bilirubin (TBIL), and red blood cells (RBC) in the high-CRF group were significantly greater than those in the low-CRF group. The standard deviations in the red cell distribution width (RDW-SD) in the high-CRF group were significantly lower than those of the low-CRF group. There were no significant differences in the other indicators (Table 2).

Table 2. Statistical values of the independent sample $\mathrm{T}$ test for biochemical indexes in the low- and high-CRF groups (mean $\pm \mathrm{SD}$ ).

\begin{tabular}{ccccc}
\hline & Low & High & $t$ & $p$ \\
\hline DBIL & $4.9 \pm 2.53(\mathrm{umol} / \mathrm{L})$ & $6.43 \pm 2.3(\mathrm{umol} / \mathrm{L})$ & $-2.18^{*}$ & 0.035 \\
TBIL & $16.56 \pm 8.14$ & $21.64 \pm 8.73$ & $-2.09^{*}$ & 0.042 \\
NEUT & $3.19 \pm 1.34\left(10^{\wedge} 9 / \mathrm{L}\right)$ & $3.55 \pm 1.16\left(10^{\wedge} 9 / \mathrm{L}\right)$ & -1.00 & 0.322 \\
LYMPH & $2.46 \pm 0.56\left(10^{\wedge} / \mathrm{L}\right)$ & $2.56 \pm 0.51\left(10^{\wedge} 9 / \mathrm{L}\right)$ & -0.64 & 0.528 \\
EO & $0.10 \pm 0.07\left(10^{\wedge} 9 / \mathrm{L}\right)$ & $0.08 \pm 0.07\left(10^{\wedge} 9 / \mathrm{L}\right)$ & 0.95 & 0.346 \\
RBC & $5.31 \pm 0.53\left(10^{\wedge} 9 / \mathrm{L}\right)$ & $5.87 \pm 0.42\left(10^{\wedge} 9 / \mathrm{L}\right)$ & $-3.97^{* * *}$ & $<0.001$ \\
HGB & $163.20 \pm 19.53(\mathrm{~g} / \mathrm{L})$ & $180.17 \pm 13.41(\mathrm{~g} / \mathrm{L})$ & $-3.48^{* * *}$ & $<0.001$ \\
RDW-SD & $42.70 \pm 3.11(\%)$ & $40.22 \pm 2.56(\%)$ & $3.00^{* *}$ & 0.004 \\
\hline
\end{tabular}

TBIL: total bilirubin; DBIL: direct bilirubin; NEUT: neutrophil count; LYMPH: lymphocyte; EO: eosinophil count RBC: red blood cells; HGB: hemoglobin; HCT: hematocrit; RDW-SD: standard deviation in red cell distribution width; ${ }^{*} p \leq 0.05 ;{ }^{* *} p \leq 0.01 ;{ }^{* *} p \leq 0.001$.

\subsection{Multiple Regression Analysis}

\subsubsection{Hippocampus Subfields}

Multiple linear regression analyses in the two CRF groups, adjusted for hippocampal total volume, were used to investigate possible associations between amygdala subfields volumetrics and biochemical parameters (Tables 3 and 4). The regression analysis within the 
two groups showed that HGB (hemoglobin) effectively positively predicted the volumes of the right subiculum body (Beta $=0.70, \mathrm{r}^{2}=0.11, p<0.05$, FDR corrected) and right presubiculum body (Beta $=0.55, \mathrm{r}^{2}=0.11, p<0.05$, FDR corrected). In the low-CRF group, the eosinophil (EO) predicted the left GC_ML_DG head volume (Beta $=-0.53, \mathrm{r}^{2}=0.37$, $p<0.05$, FDR corrected). The EO (Beta $=-0.49, \mathrm{r}^{2}=0.38, p<0.05$, FDR corrected) predicted the left CA4 head volume. The NEUT predicted the right subiculum body (NEUT, Beta $=0.48, \mathrm{r}^{2}=0.23, p<0.05$, FDR corrected) and the right presubiculum body volume (Beta $=0.73, \mathrm{r}^{2}=0.53, p<0.05$, FDR corrected). In the high-CRF group, the direct bilirubin (DBIL) predicted the left GC_ML_DG head (Beta $=-0.45, \mathrm{r}^{2}=0.25, p<0.05$, FDR corrected) volume and the left CA4 head (Beta $=-0.44, \mathrm{r}^{2}=0.19, p<0.05$, FDR corrected) volume.

Table 3. Multiple linear regression analysis of the hippocampal subregion, amygdala subregion, and biochemical indexes within the two groups.

\begin{tabular}{cccccc}
\hline Dependent Variable & Predictors & B & Ser & Beta & $\boldsymbol{t}$ \\
\hline \multirow{2}{*}{ R Sub body } & Constant & 152.33 & 44.04 & & 3.459 \\
& HGB & 0.70 & 2.56 & 0.38 & 2.75 \\
R Pre body & Constant & 83.47 & 35.86 & & 2.33 \\
& HGB & 0.55 & 0.21 & 0.36 & 2.65 \\
\hline
\end{tabular}

HGB: hemoglobin; L: left hemisphere; R: right hemisphere; Sub body: subiculum body; Pre body: presubiculum body; $p<0.05$, FDR correct.

Table 4. Multiple linear regression analysis of the hippocampal subregion, amygdala subregion, and biochemical indexes for both groups.

\begin{tabular}{|c|c|c|c|c|c|c|}
\hline & $\begin{array}{l}\text { Dependent } \\
\text { Variable }\end{array}$ & Predictors & B & Ser & Beta & $t$ \\
\hline \multirow{10}{*}{ Low CRF } & \multirow{2}{*}{$\begin{array}{c}\text { L GC_ML_DG } \\
\text { head }\end{array}$} & Constant & 80.18 & 22.97 & & 3.49 \\
\hline & & $\mathrm{EO}$ & -101.75 & 26.48 & -0.49 & -3.84 \\
\hline & \multirow[t]{2}{*}{ L CA4 head } & Constant & 65.92 & 19.07 & & 3.43 \\
\hline & & EO & -91.35 & 26.54 & -0.53 & -3.44 \\
\hline & \multirow[t]{2}{*}{ R Sub body } & Constant & 228.79 & 14.37 & & 15.92 \\
\hline & & NEUT & 10.86 & 4.17 & 0.48 & 2.61 \\
\hline & \multirow{2}{*}{ R Pre body } & Constant & 125.16 & 9.10 & & 13.75 \\
\hline & & NEUT & 13.32 & 2.64 & 0.73 & 5.05 \\
\hline & \multirow[t]{2}{*}{ L CAT } & Constant & 93.703 & 46.48 & & 2.029 \\
\hline & & EO & -744.84 & 302.94 & -0.63 & -3.35 \\
\hline \multirow{4}{*}{ High CRF } & \multirow[t]{2}{*}{$\begin{array}{c}\text { L GC_ML_DG } \\
\text { head }\end{array}$} & Constant & 208.01 & 13.17 & & 15.80 \\
\hline & & DBIL & -4.61 & -1.74 & -0.45 & -2.65 \\
\hline & \multirow[t]{2}{*}{ L CA4 head } & Constant & 60.99 & 41.39 & & 1.47 \\
\hline & & TBIL & -3.40 & 1.31 & -0.44 & -2.60 \\
\hline
\end{tabular}

EO: eosinophil; NEUT: neutrophil; RBC: red blood cells; DBIL: direct bilirubin; TBIL: total bilirubin; L: left hemisphere; R: right hemisphere; GC-ML-DG head: granule cell layers of the dentate gyrus; CA4 head: cornuammonis 4 head; Sub body: subiculum body; Pre body: presubiculum body; CAT: corticoamygdaloid transition; $p<0.05$, FDR corrected.

\subsubsection{Amygdala Subfields}

Multiple linear regression analysis (adjusted amygdala total volume) showed that the amygdala and biochemical parameters were also related in the two CRF groups (Table 4). In the low-CRF group, the EO predicted the left corticoamygdaloid transition volume (Beta $=-0.626, \mathrm{r}^{2}=0.21 p<0.05$, FDR corrected).

\section{Discussion}

To our knowledge, this is the first study to explore the effects of CRF on hippocampus and amygdala volumes under a real high-altitude environment. This study found that there were significant differences in the hippocampal and amygdala subregions related to 
CRF levels. When compared with the low-CRF group, the volumes of the hippocampus and amygdala subfields were improved in the high-CRF group, and these changes were associated with lower inflammatory responses. This suggests the existence of a relationship between CRF levels and volume changes in the hippocampus and amygdala in high-altitude environments, which may be associated with hypoxia stress.

Previous studies have found that hypoxia severely affects gray matter volumes in the hippocampus and amygdala [44]. In this study, we found that the gray matter volume in the hippocampal subfields and amygdala subfields were increased in the high-CRF group when high-altitude participants were divided into two groups according to median $\mathrm{VO}_{2 \max }$. This indicates that resilient cardiorespiratory function in high-altitude environments effectively protects against the negative effects of high altitude and a low oxygen environment on the hippocampus and amygdala. Previous literature has focused on analysis of the relationship between the volume of subcortical brain structures and CRF, and have found that higher levels of CRF are associated with greater volumes in the hippocampus and basal ganglia $[45,46]$. Correspondingly, increased CRF is associated with an increase in general cortical thickness [47], and higher CRF levels are associated with higher brainderived neurotrophic factor (BDNF) levels, especially in the hippocampus. Increased hippocampal volume is positively correlated with BDNF levels [22]. Additionally, higher CRF is associated with increased volume of the hippocampus and amygdala in Alzheimer's patients [22]. Better CRF improves the brain and behavior, as well as neurogenesis, in both healthy and dementia models, reduces toxicity and cerebral amyloids, and reduces inflammation and oxidative stress [48]. Consistent with these prior investigations, our findings further suggested that high CRF is significantly related to increased gray matter volume in the hippocampus and amygdala at high altitude among immigrant participants.

We found that the low-CRF group was more affected by inflammation than the highCRF group. Eosinophil effectively predicted the volume of the amygdala and hippocampal subfields in the low-CRF group. The release of cortisol relates the secretion of cytokines, especially interleukin-5, which stimulates the production and differentiation of granulocytes, such as eosinophils [49]. The inflammatory response induced by HPA axis disorder affects the volume of the hippocampus and amygdala under the stress state [50]. Inflammation is often accompanied by the apoptosis of a large number of cells and changes in the nervous system [51]. Eosinophils are important markers of inflammation and are associated with damage to neurons in the hippocampus and amygdala $[52,53]$. Eosinophils were observed in the hippocampal and amygdala neuron damage induced by state epilepsy in mice [54]. Previous studies have shown that improved lung function is associated with decreased eosinophils [55]. We also found that NEUT were effective predictors of hippocampal subfields volume in the low-CRF group. NEUT, as phagocytes, play an important role in inflammatory immune regulation [56]. Tissue damage caused by inflammation leads to the excessive activation of NEUT, which leads to an aggravated inflammatory response [57]. The accumulation of neutrophils in the brain has been associated with increased secondary brain damage and poor neurological outcomes [58]. Traumatic brain injury results in an inflammatory response in the brain, accompanied by an influx of neutrophils into the cerebral cortex and especially the hippocampus [59]. A lower CRF was also related to greater WBC, as well as neutrophil, lymphocyte, and monocyte, counts [60]. Higher CRF reduces NEUT content and improves the immune response [61,62]. Other studies have found that higher CRF produces oxidative damage in neutrophils and induces antioxidant defenses in lymphocytes [63]. Our results showed that the hippocampus and amygdala in the low-CRF group were more susceptible to inflammation at high altitudes, resulting in smaller amygdala and hippocampal volumes. However, the relationship between these parameters and the amygdala and hippocampus was not found in the high-CRF group, suggesting that high CRF can reduce the inflammatory response and improve the plasticity of the hippocampus and amygdala under high-altitude stress, which is similar to the findings in previous studies $[64,65]$. 
Oxygen is transported primarily by hemoglobin in red blood cells $[66,67]$. We found RBC and HGB were higher, and RDW-SD smaller, in the high-CRF group. RDW is a measurement of the size variation, as well as an index of the heterogeneity, of the erythrocytes (i.e., anisocytosis). Higher RDW values reflect greater variation in RBC volumes and were found to be related to many inflammation diseases in previous studies [68]. Because the erythrocyte represents the body's oxygen carrier, its redox and metabolic status is extremely important for the functioning and regulation of oxygen affinity to hemoglobin, which is determined by a number of metabolites within the erythrocyte. All tissues are dependent on RBC function, especially neurons, which use $20 \%$ of the total oxygen consumed [69]. Reduced hemoglobin levels in the hippocampus and other neurons have been found in studies of neurodegenerative diseases [70]. Increases in erythrocytes and hemoglobin are accompanied by increased hippocampal oxygenation under hypoxia [71]. On the other hand, RBCs mediate the immune system's ability to reduce inflammation and stress [72]. Another study also found that the red blood cells of physically active rats were more resistant to oxidative stress after they were deprived of oxygen [73]. Our previous study found that healthy RBC at high altitude can support the immune system [40]. Our results here showed that individuals with high CRF levels had larger hippocampal and amygdala volumes than those with low CRF levels, possibly because individuals with high CRF levels have higher oxygen transport capacity and higher immune levels.

In addition, we found that the DBIL and TBIL of the high-CRF group negatively predicted the hippocampal subfield volume, and the DBIL and TBIL in the high-CRF group was significantly increased. The increase in DBIL and TBIL may be caused by the increase in RBC and HGB. Bilirubin has been commonly considered to be simply the "final product" of heme catabolism [74]. The rise in bilirubin in rats exposed to high altitudes may be due to an increase in red blood cell counts [75]. Bilirubin is an endogenous antioxidant that plays an important role in the anti-oxidative stress and anti-inflammation of neurons $[76,77]$. Bilirubin enhances the bactericidal ability of neutrophils [78]. There is evidence that it protects the cardiovascular system, neuronal systems, the hepatobiliary system, the pulmonary system, and the immune system [74]. Mildly elevated serum bilirubin is generally associated with the attenuation of oxidative stress and with a decreased inflammatory status [79]. On the other hand, a decrease in bilirubin during hypoxia is associated with increased inflammation [80]. The accumulation of bilirubin acts as an effective defense mechanism against stress and increased inflammation [81]. In conclusion, our results suggest that higher CRF at high altitudes can reduce the hypoxic stress response, thereby inducing immunity and reducing inflammation, which may be related to increased oxygen transport capacity of the body.

There were several issues which should be considered in future works. First, a longitudinal trace study should be included to validate the present findings, in which the behavioral data including the gender difference, life style, personality, and so on should be considered. Second, the physiological characteristics of hypoxia tolerance are closely related to the genome, and this could provide a potential way to better understand the molecular mechanisms of human adaptation to high altitudes [82]. Third, the neuroinflammatory markers and the role of epigenetics should be explored related to the effects of exercise and oxygen interventions on the high-altitude participants for altitude adaptation.

\section{Conclusions}

This study indicated that higher CRF can significantly protect against the decrease in hippocampal and amygdala volume induced by high-altitude hypoxia. A better CRF might be related to a lower physiological stress response. These findings provide new insights into the stress response to hypoxia in human adaptation. 


\begin{abstract}
Author Contributions: Conceptualization, Z.-X.W. and T.-A.Z.; methodology, Z.-X.W. and D.-M.C.; software, Z.-X.W., P.D. and J.-G.W.; validation, H.L., R.S. and H.-L.M.; formal analysis, D.-L.Z.; investigation, D.-L.Z.; resources, H.-L.M.; data curation, Z.-X.W.; writing-original draft preparation, Z.-X.W.; writing-review and editing, Z.-X.W.; visualization, Z.-X.W.; supervision, D.-L.Z. and H.L.M.; project administration, H.-L.M.; funding acquisition, H.-L.M. and D.-L.Z. All authors have read and agreed to the published version of the manuscript.
\end{abstract}

Funding: This work was supported by the National Natural Science Foundation of China (31660274, 31771247, and 31600907), the Reformation and Development Funds for Local Region Universities from the Chinese Government in 2020 (00060607, ZCJK 2020-11), and the High-Level Postgradu-ate Talent Training Program of Tibet University (2019-GSP-S108).

Institutional Review Board Statement: This study was conducted in accordance with the Declaration of Helsinki, and approved by the Institutional Review Board (or Ethics Committee) of the Ethics Committee of Tibet University.

Informed Consent Statement: Informed consent was obtained from all subjects involved in the study. Written informed consent was obtained from the patient(s) to publish this paper.

Data Availability Statement: Data materials can be obtained by contacting the corresponding author.

Conflicts of Interest: The authors declare no conflict of interest.

\title{
References
}

1. Hossmann, K.-A. The Hypoxic Brain. In Hypoxia: Into the Next Millennium; Roach, R.C., Wagner, P.D., Hackett, P.H., Eds.; Springer: Boston, MA, USA, 1999; pp. 155-169.

2. Kumari, P.; Kauser, H.; Wadhwa, M.; Roy, K.; Alam, S.; Sahu, S.; Kishore, K.; Ray, K.; Panjwani, U. Hypobaric hypoxia impairs cued and contextual fear memory in rats. Brain Res. 2018, 1692, 118-133. [CrossRef] [PubMed]

3. Maiti, P.; Singh, S.B.; Mallick, B.; Muthuraju, S.; Ilavazhagan, G. High altitude memory impairment is due to neuronal apoptosis in hippocampus, cortex and striatum. J. Chem. Neuroanat. 2008, 36, 227-238. [CrossRef] [PubMed]

4. Zhang, J.; Zhang, H.; Li, J.; Chen, J.; Han, Q.; Lin, J.; Yang, T.; Fan, M. Adaptive Modulation of Adult Brain Gray and White Matter to High Altitude: Structural MRI Studies. PLoS ONE 2013, 8, e68621. [CrossRef]

5. Ma, H.; Huang, X.; Liu, M.; Ma, H.; Zhang, D. Aging of stimulus-driven and goal-directed attentional processes in young immigrants with long-term high altitude exposure in Tibet: An ERP study. Sci. Rep. 2018, 8, 17417. [CrossRef]

6. Zhang, D.; Zhang, X.; Ma, H.; Wang, Y.; Ma, H.; Liu, M. Competition among the attentional networks due to resource reduction in Tibetan indigenous residents: Evidence from event-related potentials. Sci. Rep. 2018, 8, 610. [CrossRef] [PubMed]

7. McEwen, B.S. Physiology and Neurobiology of Stress and Adaptation: Central Role of the Brain. Physiol. Rev. 2007, 87, 873-904. [CrossRef]

8. Rybnikova, E.; Nalivaeva, N. Glucocorticoid-Dependent Mechanisms of Brain Tolerance to Hypoxia. Int. J. Mol. Sci. 2021, 22, 7982. [CrossRef]

9. Zhao, F.; Yang, J.; Cui, R. Effect of Hypoxic Injury in Mood Disorder. Neural Plast. 2017, 2017, 6986983. [CrossRef]

10. Gainey, S.J. Hypoxic immunomodulation results in increased disease risk and altered behavior via non-canonical pathways. Ph.D. Thesis, University of Illinois at Urbana-Champaign, Champaign, IL, USA, 28 February 2017.

11. Yang, T.; Zhou, D.; Stefan, H. Why mesial temporal lobe epilepsy with hippocampal sclerosis is progressive: Uncontrolled inflammation drives disease progression? J. Neurol. Sci. 2010, 296, 1-6. [CrossRef]

12. Zhang, J.; Malik, A.; Choi, H.B.; Ko, R.W.; Dissing-Olesen, L.; MacVicar, B.A. Microglial CR3 Activation Triggers Long-Term Synaptic Depression in the Hippocampus via NADPH Oxidase. Neuron 2014, 82, 195-207. [CrossRef]

13. Feng, J.-F.; Zhao, X.; Gurkoff, G.G.; Van, K.C.; Shahlaie, K.; Lyeth, B.G. Post-Traumatic Hypoxia Exacerbates Neuronal Cell Death in the Hippocampus. J. Neurotrauma 2012, 29, 1167-1179. [CrossRef] [PubMed]

14. Michalak, Z.; Obari, D.; Ellis, M.; Thom, M.; Sisodiya, S.M. Neuropathology of SUDEP. Neurology 2017, 88, 551-561. [CrossRef] [PubMed]

15. Xu, L.-H.; Xie, H.; Shi, Z.-H.; Du, L.-D.; Wing, Y.-K.; Li, A.M.; Ke, Y.; Yung, W.-H. Critical Role of Endoplasmic Reticulum Stress in Chronic Intermittent Hypoxia-Induced Deficits in Synaptic Plasticity and Long-Term Memory. Antioxid. Redox Signal. 2015, 23, 695-710. [CrossRef] [PubMed]

16. Carty, M.L.; Wixey, J.A.; Kesby, J.; Reinebrant, H.E.; Colditz, P.B.; Gobe, G.; Buller, K.M. Long-term losses of amygdala corticotropin-releasing factor neurons are associated with behavioural outcomes following neonatal hypoxia-ischemia. Behav. Brain Res. 2010, 208, 609-618. [CrossRef]

17. Suliga, E. Chapter 4-Lifestyle Factors Affecting Abdominal Obesity in Children and Adolescents: Risks and Benefits. In Nutrition in the Prevention and Treatment of Abdominal Obesity; Watson, R.R., Ed.; Academic Press: San Diego, CA, USA, 2014 ; pp. 39-56.

18. Johnson, N.F.; Kim, C.; Clasey, J.L.; Bailey, A.; Gold, B.T. Cardiorespiratory fitness is positively correlated with cerebral white matter integrity in healthy seniors. NeuroImage 2012, 59, 1514-1523. [CrossRef] 
19. Lee, J.T.; Chaloner, E.J.; Hollingsworth, S.J. The role of cardiopulmonary fitness and its genetic influences on surgical outcomes. Br. J. Surg. 2005, 93, 147-157. [CrossRef]

20. Sapolsky, R.M. Glucocorticoids and Hippocampal Atrophy in Neuropsychiatric Disorders. Arch. Gen. Psychiatry 2000, 57, 925-935. [CrossRef]

21. Lucassen, P.J.; Meerlo, P.; Naylor, A.S.; van Dam, A.M.; Dayer, A.G.; Fuchs, E.; Oomen, C.A.; Czéh, B. Regulation of adult neurogenesis by stress, sleep disruption, exercise and inflammation: Implications for depression and antidepressant action. Eur. Neuropsychopharmacol. 2010, 20, 1-17. [CrossRef]

22. Boots, E.; Schultz, S.; Oh, J.M.; Larson, J.; Edwards, D.; Cook, D.; Koscik, R.L.; Dowling, M.N.; Gallagher, C.L.; Carlsson, C.M.; et al. Cardiorespiratory fitness is associated with brain structure, cognition, and mood in a middle-aged cohort at risk for Alzheimer's disease. Brain Imaging Behav. 2014, 9, 639-649. [CrossRef]

23. Prathap, S.; Nagel, B.J.; Herting, M.M. Understanding the role of aerobic fitness, spatial learning, and hippocampal subfields in adolescent males. Sci. Rep. 2021, 11, 9311. [CrossRef]

24. Erickson, K.I.; Prakash, R.S.; Voss, M.W.; Chaddock, L.; Hu, L.; Morris, K.S.; White, S.M.; Wójcicki, T.R.; McAuley, E.; Kramer A.F. Aerobic fitness is associated with hippocampal volume in elderly humans. Hippocampus 2009, 19, 1030-1039. [CrossRef] [PubMed]

25. Herting, M.M.; Nagel, B.J. Aerobic fitness relates to learning on a virtual Morris Water Task and hippocampal volume in adolescents. Behav. Brain Res. 2012, 233, 517-525. [CrossRef] [PubMed]

26. Lin, T.-W.; Shih, Y.-H.; Chen, S.-J.; Lien, C.-H.; Chang, C.-Y.; Huang, T.-Y.; Chen, S.-H.; Jen, C.J.; Kuo, Y.-M. Running exercise delays neurodegeneration in amygdala and hippocampus of Alzheimer's disease (APP/PS1) transgenic mice. Neurobiol. Learn. Mem. 2015, 118, 189-197. [CrossRef]

27. Seo, B.; Kim, D.; Choi, D.; Kwon, C.; Shin, H. The Effect of Electrical Stimulation on Blood Lactate after Anaerobic Muscle Fatigue Induced in Taekwondo Athletes. J. Phys. Ther. Sci. 2011, 23, 271-275. [CrossRef]

28. Heath, E.H. ACSM's Guidelines for Exercise Testing and Prescription, 7th ed.; Lippincott Williams \& Wilkins: Philadelphia, PA, USA, 2005; p. 37.

29. Grocott, M.; Montgomery, H.; Vercueil, A. High-altitude physiology and pathophysiology: Implications and relevance for intensive care medicine. Crit. Care 2007, 11, 203. [CrossRef]

30. Ward, S.A.; Grocott, M.P.; Levett, D.Z. Exercise testing, supplemental oxygen, and hypoxia. Ann. Am. Thorac. Soc. 2017, 14, S140-S148. [CrossRef] [PubMed]

31. Mairbäurl, H. Red blood cells in sports: Effects of exercise and training on oxygen supply by red blood cells. Front. Physiol. 2013, 4, 332. [CrossRef]

32. Kleppe, S.; Bernhardt, C.; Wölfle, J.; Breuer, J. Red Blood Cell Function in Hypoxia at Altitude and Exercise. Int. J. Sports Med. 1994, 15, 51-63.

33. Ogoh, S.; Ainslie, P.N. Regulatory Mechanisms of Cerebral Blood Flow during Exercise: New Concepts. Exerc. Sport Sci. Rev. 2009, 37, 123-129. [CrossRef]

34. Smith, T.B.; Stonell, C.; Purkayastha, S.; Paraskevas, P. Cardiopulmonary exercise testing as a risk assessment method in non cardio-pulmonary surgery: A systematic review. Anaesthesia 2009, 64, 883-893. [CrossRef]

35. Grover, R.F.; Weil, J.V.; Reeves, J.T. Cardiovascular adaptation to exercise at high altitude. Exerc. Sport Sci. Rev. 1986, 14, 269-302. [CrossRef] [PubMed]

36. Haugen, A.H.; Melanson, E.L.; Tran, Z.V.; Kearney, J.T.; Hill, J.O. Variability of measured resting metabolic rate. Am. J. Clin. Nutr. 2003, 78, 1141-1144. [CrossRef] [PubMed]

37. Mala, L.; Maly, T.; Zahalka, F.; Heller, J.; Hrasky, P.; Vodicka, P. Differences in the morphological and physiological charac-teristics of senior and junior elite Czech judo athletes. Arch. Budo 2015, 11, 217-226.

38. Iglesias, J.E.; Augustinack, J.C.; Nguyen, K.; Player, C.M.; Player, A.; Wright, M.; Roy, N.; Frosch, M.P.; McKee, A.C.; Wald, L.; et al. A computational atlas of the hippocampal formation using ex vivo, ultra-high resolution MRI: Application to adaptive segmentation of in vivo MRI. NeuroImage 2015, 115, 117-137. [CrossRef] [PubMed]

39. Saygin, Z.; Kliemann, D.; Iglesias, J.E.; van der Kouwe, A.; Boyd, E.; Reuter, M.; Stevens, A.; Van Leemput, K.; McKee, A.; Frosch M.; et al. High-resolution magnetic resonance imaging reveals nuclei of the human amygdala: Manual segmentation to automatic atlas. NeuroImage 2017, 155, 370-382. [CrossRef]

40. Xue, X.-J.; Su, R.; Li, Z.-F.; Bu, X.-O.; Dang, P.; Yu, S.-F.; Wang, Z.-X.; Chen, D.-M.; Zeng, T.-A.; Liu, M.; et al. Oxygen Metabolisminduced Stress Response Underlies Heart-brain Interaction Governing Human Consciousness-breaking and Attention. Neurosci. Bull. 2021, 38, 166-180. [CrossRef]

41. Liu, S.; Zhao, Y.; Ren, Q.; Gong, G.; Zhang, D.; Shao, K.; Lin, P.; Yuan, Y.; Dai, T.; Zhang, Y.; et al. Research Square 2021. Available online: https://assets.researchsquare.com/files/rs-900442/v1/7c67881d-baba-4d40-b494-bd49d882bd54.pdf?c=1632165377 (accessed on 25 February 2022).

42. Brown, S.S.G.; Rutland, J.W.; Verma, G.; Feldman, R.E.; Alper, J.; Schneider, M.; Delman, B.; Murrough, J.M.; Balchandani, P. Structural MRI at 7T reveals amygdala nuclei and hippocampal subfield volumetric association with Major Depressive Disorder symptom severity. Sci. Rep. 2019, 9, 10166. [CrossRef]

43. Benjamini, Y.; Hochberg, Y. Controlling the False Discovery Rate: A Practical and Powerful Approach to Multiple Testing. J. R. Stat. Soc. Ser. B 1995, 57, 289-300. [CrossRef] 
44. Haukvik, U.K.; McNeil, T.; Lange, E.H.; Melle, I.; Dale, A.M.; Andreassen, O.A.; Agartz, I. Pre- and perinatal hypoxia associated with hippocampus/amygdala volume in bipolar disorder. Psychol. Med. 2013, 44, 975-985. [CrossRef]

45. Chaddock, L.; Erickson, K.I.; Prakash, R.S.; Kim, J.S.; Voss, M.W.; Vanpatter, M.; Pontifex, M.B.; Raine, L.B.; Konkel, A.; Hillman, C.H.; et al. A neuroimaging investigation of the association between aerobic fitness, hippocampal volume, and memory performance in preadolescent children. Brain Res. 2010, 1358, 172-183. [CrossRef]

46. Chaddock, L.; Hillman, C.; Pontifex, M.; Johnson, C.R.; Raine, L.B.; Kramer, A. Childhood aerobic fitness predicts cognitive performance one year later. J. Sports Sci. 2012, 30, 421-430. [CrossRef] [PubMed]

47. Engeroff, T.; Füzéki, E.; Vogt, L.; Fleckenstein, J.; Schwarz, S.; Matura, S.; Pilatus, U.; Deichmann, R.; Hellweg, R.; Pantel, J.; et al Is Objectively Assessed Sedentary Behavior, Physical Activity and Cardiorespiratory Fitness Linked to Brain Plasticity Outcomes in Old Age? Neuroscience 2018, 388, 384-392. [CrossRef] [PubMed]

48. Daniele, T.M.D.C.; de Bruin, P.F.C.; de Matos, R.S.; de Bruin, G.S.; Chaves, C.M.; de Bruin, V.M.S. Exercise effects on brain and behavior in healthy mice, Alzheimer's disease and Parkinson's disease model-A systematic review and meta-analysis. Behav. Brain Res. 2020, 383, 112488. [CrossRef]

49. Segerstrom, S.C.; Miller, G.E. Psychological Stress and the Human Immune System: A Meta-Analytic Study of 30 Years of Inquiry. Psychol. Bull. 2004, 130, 601-630. [CrossRef] [PubMed]

50. Majidi, J.; Kosari-Nasab, M.; Salari, A.-A. Developmental minocycline treatment reverses the effects of neonatal immune activation on anxiety- and depression-like behaviors, hippocampal inflammation, and HPA axis activity in adult mice. Brain Res. Bull. 2016, 120, 1-13. [CrossRef]

51. Dickens, A.M.; Tovar-Y-Romo, L.B.; Yoo, S.-W.; Trout, A.L.; Bae, M.; Kanmogne, M.; Megra, B.; Williams, D.W.; Witwer, K.W.; Gacias, M.; et al. Astrocyte-shed extracellular vesicles regulate the peripheral leukocyte response to inflammatory brain lesions. Sci. Signal. 2017, 10, eaai7696. [CrossRef]

52. Collombet, J.-M.; Piérard, C.; Béracochéa, D.; Coubard, S.; Burckhart, M.-F.; Four, E.; Masqueliez, C.; Baubichon, D.; Lallement, G. Long-term consequences of soman poisoning in mice: Part 1. Neuropathology and neuronal regeneration in the amygdala. Behav. Brain Res. 2008, 191, 88-94. [CrossRef]

53. Men, S.; Lee, D.H.; Barron, J.R.; Muñoz, D.G. Selective Neuronal Necrosis Associated with Status Epilepticus: MR Findings. Am. J. Neuroradiol. 2000, 21, 1837-1840.

54. Loss, C.M.; Córdova, S.D.; de Oliveira, D.L. Ketamine reduces neuronal degeneration and anxiety levels when administered during early life-induced status epilepticus in rats. Brain Res. 2012, 1474, 110-117. [CrossRef]

55. Handayani, R.N.; Yunus, F.; Ibrahim, E.I.; Rengganis, I. Correlation between Improve Lung Function with Decrease of Eosinophil Levels in Atopic Asthma Persistent After Asthma Exercise. Ann. Trop. Med. Public Heal. 2019, 22, 338-346. [CrossRef]

56. Bae, G.H.; Lee, H.Y.; Jung, Y.S.; Shim, J.W.; Kim, S.D.; Baek, S.-H.; Kwon, J.Y.; Park, J.S.; Bae, Y.-S. Identification of novel peptides that stimulate human neutrophils. Exp. Mol. Med. 2012, 44, 130-137. [CrossRef] [PubMed]

57. Pillay, J.; Hietbrink, F.; Koenderman, L.; Leenen, L. The systemic inflammatory response induced by trauma is reflected by multiple phenotypes of blood neutrophils. Injury 2007, 38, 1365-1372. [CrossRef] [PubMed]

58. Stahel, P.F.; Morganti-Kossmann, C.; Kossmann, T. The role of the complement system in traumatic brain injury. Brain Res. Rev. 1998, 27, 243-256. [CrossRef]

59. Keeling, K.; Hicks, R.; Mahesh, J.; Billings, B.; Kotwal, G. Local neutrophil influx following lateral fluid-percussion brain injury in rats is associated with accumulation of complement activation fragments of the third component (C3) of the complement system. J. Neuroimmunol. 2000, 105, 20-30. [CrossRef]

60. Craige, S.M.; Kant, S.; Jr, J.F.K. Reactive Oxygen Species in Endothelial Function: From Disease to Adaptation. Circ. J. 2015, 79, 1145-1155. [CrossRef] [PubMed]

61. Mooren, F.C.; Blöming, D.; Lechtermann, A.; Lerch, M.M.; Völker, K. Lymphocyte apoptosis after exhaustive and moderate exercise. J. Appl. Physiol. 2002, 93, 147-153. [CrossRef] [PubMed]

62. Suzuki, K.; Sato, H.; Kikuchi, T.; Abe, T.; Nakaji, S.; Sugawara, K.; Totsuka, M.; Sato, K.; Yamaya, K. Capacity of circulating neutrophils to produce reactive oxygen species after exhaustive exercise. J. Appl. Physiol. 1996, 81, 1213-1222. [CrossRef]

63. Ferrer, M.D.; Tauler, P.; Sureda, A.; Tur, J.A.; Pons, A. Antioxidant regulatory mechanisms in neutrophils and lymphocytes after intense exercise. J. Sports Sci. 2009, 27, 49-58. [CrossRef]

64. Stults-Kolehmainen, M.A.; Sinha, R. The Effects of Stress on Physical Activity and Exercise. Sports Med. 2013, 44, 81-121. [CrossRef]

65. Wärnberg, J.; Cunningham, K.; Romeo, J.; Marcos, A. Physical activity, exercise and low-grade systemic inflammation. Proc. Nutr. Soc. 2010, 69, 400-406. [CrossRef]

66. D’Alessandro, A.; Nemkov, T.; Sun, K.; Liu, H.; Song, A.; Monte, A.A.; Subudhi, A.W.; Lovering, A.T.; Dvorkin, D.; Julian, C.G.; et al. AltitudeOmics: Red Blood Cell Metabolic Adaptation to High Altitude Hypoxia. J. Proteome Res. 2016, 15, $3883-3895$. [CrossRef] [PubMed]

67. Risso, A.; Turello, M.; Biffoni, F.; Antonutto, G. Red blood cell senescence and neocytolysis in humans after high altitude acclimatization. Blood Cells Mol. Dis. 2007, 38, 83-92. [CrossRef] [PubMed]

68. Celik, A.; Aydin, N.; Ozcirpici, B.; Saricicek, E.; Sezen, H.; Okumus, M.; Bozkurt, S.; Kilinc, M. Elevated red blood cell distri-bution width and inflammation in printing workers. Med. Sci. Monit. 2013, 19, 1001-1005. [PubMed] 
69. Wojsiat, J.; Laskowska-Kaszub, K.; Mietelska-Porowska, A.; Wojda, U. Search for Alzheimer's disease biomarkers in blood cells: Hypotheses-driven approach. Biomarkers Med. 2017, 11,917-931. [CrossRef]

70. Ferrer, I.; Gómez, A.; Carmona, M.; Huesa, G.; Porta, S.; Riera-Codina, M.; Biagioli, M.; Gustincich, S.; Aso, E. Neuronal Hemoglobin is Reduced in Alzheimer's Disease, Argyrophilic Grain Disease, Parkinson's Disease, and Dementia with Lewy Bodies. J. Alzheimers Dis. 2011, 23, 537-550. [CrossRef]

71. Schelshorn, D.W.; Schneider, A.; Kuschinsky, W.; Weber, D.; Krüger, C.; Dittgen, T.; Bürgers, H.F.; Sabouri, F.; Gassler, N.; Bach, A.; et al. Expression of Hemoglobin in Rodent Neurons. J. Cereb. Blood Flow Metab. 2008, 29, 585-595. [CrossRef]

72. Buttari, B.; Profumo, E.; Riganò, R. Crosstalk between Red Blood Cells and the Immune System and Its Impact on Atherosclerosis BioMed. Res. Int. 2015, 2015, 616834. [CrossRef]

73. Devi, S.A.; Subramanyam, M.; Vani, R.; Jeevaratnam, K. Adaptations of the antioxidant system in erythrocytes of trained adult rats: Impact of intermittent hypobaric-hypoxia at two altitudes. Comp. Biochem. Physiol. Part C Toxicol. Pharmacol. 2005, 140, 59-67. [CrossRef]

74. Otero Regino, W.; Velasco, H.; Sandoval, H. Papel protector de la bilirrubina en el ser humano. Rev. Colomb. Gastroenterología 2009, 24, 293-301. (In Spanish)

75. Altland, P.D.; Parker, M.G. Bilirubinemia and intravascular hemolysis during acclimatization to high altitude. Int. J. Biometeorol. 1977, 21, 165-170. [CrossRef]

76. Dani, C.; Poggi, C.; Fancelli, C.; Pratesi, S. Changes in bilirubin in infants with hypoxic-ischemic encephalopathy. Eur. J. Pediatr. 2018, 177, 1795-1801. [CrossRef] [PubMed]

77. Vaz, A.R.; Silva, S.L.; Barateiro, A.; Falcão, A.S.; Fernandes, A.; Brito, M.A.; Brites, D. Selective vulnerability of rat brain regions to unconjugated bilirubin. Mol. Cell. Neurosci. 2011, 48, 82-93. [CrossRef] [PubMed]

78. Thong, Y.; Ness, D.; Ferrante, A. Effect of bilirubin on the fungicidal capacity of human neutrophils. Med. Mycol. 1979, 17, 125-129. [CrossRef] [PubMed]

79. Zelenka, J.; Dvořák, A.; Alán, L.; Zadinová, M.; Haluzik, M.; Vítek, L. Hyperbilirubinemia Protects against Aging-Associated Inflammation and Metabolic Deterioration. Oxidative Med. Cell. Longev. 2016, 2016, 6190609. [CrossRef] [PubMed]

80. Friedlander, A.H.; Boström, K.I.; Tran, H.-A.; Chang, T.I.; Polanco, J.C.; Lee, U.K. Severe Sleep Apnea Associated with Increased Systemic Inflammation and Decreased Serum Bilirubin. J. Oral Maxillofac. Surg. 2019, 77, 2318-2323. [CrossRef]

81. Zelenka, J.; Muchova, L.; Zelenkova, M.; Vanova, K.; Vreman, H.J.; Wong, R.J.; Vitek, L. Intracellular accumulation of bilirubin as a defense mechanism against increased oxidative stress. Biochimie 2012, 94, 1821-1827. [CrossRef]

82. Julian, C.G. Epigenomics and human adaptation to high altitude. J. Appl. Physiol. 2017, 123, 1362-1370. [CrossRef] 